\title{
Africa and Technology Exchange: Is Financial Aid Effective for the Development of the Continent?
}

\author{
Sergey V. Rastoropov, Elvira N. Iamalova², Natalia A. Sadovnikova ${ }^{3}$, Igbal A. Guliev, \\ ${ }^{1}$ University of the Prosecutors of the Russian Federation, Moscow, Russia \\ ${ }^{2}$ Department of Ethics, Cultural Studies and Public Relations, Bashkir State University, Ufa, Russia \\ ${ }^{3}$ Department of Statistics, Plekhanov Russian University of Economics, Moscow, Russia \\ ${ }^{4}$ International Institute of Energy Policy and Diplomacy, MGIMO University, Moscow, Russia
}

Received July 18, 2021; Revised September 7, 2021; Accepted September 21, 2021

\section{Cite This Paper in the following Citation Styles}

(a): [1] Sergey V. Rastoropov, Elvira N. Iamalova, Natalia A. Sadovnikova, Igbal A. Guliev, "Africa and Technology Exchange: Is Financial Aid Effective for the Development of the Continent?," Universal Journal of Accounting and Finance, Vol. 9, No. 5, pp. 1134 - 1141, 2021. DOI: 10.13189/ujaf.2021.090523.

(b): Sergey V. Rastoropov, Elvira N. Iamalova, Natalia A. Sadovnikova, Igbal A. Guliev (2021). Africa and Technology Exchange: Is Financial Aid Effective for the Development of the Continent?. Universal Journal of Accounting and Finance, 9(5), 1134 - 1141. DOI: 10.13189/ujaf.2021.090523.

Copyright $\bigcirc 2021$ by authors, all rights reserved. Authors agree that this article remains permanently open access under the terms of the Creative Commons Attribution License 4.0 International License

\begin{abstract}
Africa, despite continued and substantial financial assistance from more developed countries, has not yet achieved significant economic growth. It can be concluded that the assistance format requires adjustment. As a new information society is being formed, it can be supposed that the transfer of many technologies to African countries can significantly improve their situation. Thus, the authors put forward the hypothesis that in order to boost the development of African countries, the transfer of basic industrial technologies is needed. The major challenge of the article was to create a model, incorporating both economic indicators of growth and the volume of aid to the African countries, as the second parameter is hard to estimate. Within the developed hypothesis, proposals are put forward for the formation of technological convergence specific mechanisms through supranational institutions. The main aim of the article is to confirm the hypothesis, and put forward four schemes for the formation of the technological exchange infrastructure on the continent. In addition to that, the article provides basic directions for the institutional cooperation between the international development institutions. The key contribution of the article is the proof that the international development institutions' activity and their aid don't correlate with the economic development of the African countries, thus they don't have a significant economic influence.
\end{abstract}

Keywords Africa, Technology, Convergence,
Development Institutions, Efficiency

\section{Introduction}

Today, as 50 years ago, Africa is one of the least world's developed regions. The main difference is that from 1970 regions such as Asia, in particular, Southeast Asia or South America, have significantly improved their position and economic development level over these 50 years. It cannot be denied that many of them still belong to the least developed countries, and they have to seek funds for their life through international lending and support to LDCs, but they have the prospect of breaking the poverty vicious cycle, thanks to regional integration initiatives. Africa and especially its central part, both were and remain LDCs without the development prospects of their economies. They rely entirely on foreign aid [1].

A similar situation is observed in Oceania, but in this region, the problem lies in the low growth potential for natural and demographic reasons (small territory and small population). Nevertheless, the amount of aid allocated to African countries is extremely large. Moreover, half of IDA's credit resources go to African countries and other development banks' resources also go to African countries. This raises the question about the effectiveness of financial assistance in African countries and whether there is a better 
alternative to put them in a sustainable development way.

The authors suppose that the transfer of basic industrial technologies is the stimulus for the boost in the development of African countries. To prove this hypothesis, the authors solve the following problems: the assistance inefficiency from developed countries and their institutions is proved, and assistance politicization is also possible; it is proved that the development of basic industries in Africa will lead to the growth of the continent's economies and the authors suggest mechanism to redistribute this growth effects for LDCs. Also, the authors consider a possible track of the continent's technological transformation's development, taking into account the African countries' interests.

\section{Literature Review}

The issue of the aid effectiveness for the African countries is a highly discussed theme from the very start of the aid itself. The authors would like to point out, that many scientists, for instance or [3], [21], [6] don't stick to a firm opinion on aid effectiveness, either pointing out that macroeconomic data isn't the key indicator for the regional development or that the aid itself is controversial in its effects without regard to the region it's offered. Instead of providing instruments of aid effectiveness monitoring, IMF offers controversial recommendations on aid effectiveness growth [10]. The analysis of other sources, for instance, [11] and [8] demonstrates that political component of aid provision in Africa plays an important (if not the major) role in aid dynamics in Africa, while the instability in developed countries, according to [4], determines the dynamics of aid to Africa. These sources provided an idea of correlation analysis of aid volume and GDP growth in Africa, which is carried out in this article.

At the same time, the practice of aid provision to the least developed economies may be useful, or, at least, inevitable, especially when we speak of the climate change aid or the aid in overcoming the crises (https://journals.sagepub.com/doi/10.1177/000203972090 5598). The reasoning of such aid lies in the provision of response to the global challenges, not the regional development; and hence, this type of aid is economically grounded. The other interesting idea is to use the crisis (which is a rather permanent condition in the researched economies) as the boost for the further development, just as in case of the COVID-2019 crisis possible positive impact on the African economies [23].

At the same time, the role of the African development bank in attracting aid, covered in and its structure efficiency [5] provide the ground for further research in the direction of AfDB-aid effectiveness correlation in Africa. In any case, the countries, which possess the natural resources, as for instance, Botswana, are in privileged position in aid reception, moreover, they have some episodic positive effects of aid on the economy, but their economic development makes them dependent from the foreign investors [24].

\section{Methodology}

The authors divide the technologies into two groups: basic industrial technologies and transitional technologies. The grouping of the technologies is based on the following factor: if the industry on the current stage of its development taken in the separate region (for instance, in this paper Africa in general, excluding Northern Africa and SAR) can be developed only with the use of a concrete technology, while the addition of other factors of production (labor, capital etc.) will lead to the little or no growth, such technology is basic industrial. If the industry still can develop extensively, with the help of the growth of production factors costs, the technology is transitional. This classification varies in different regions and countries. It is important, as it allows figuring out which technologies have a significant impact on the development of the industry in general and which affect only several sectors of the industry.

To solve the tasks of the paper, the authors use the following methodology: the economic growth of the selected region has been estimated as the arithmetic average over the period, the period researched is 1970-2020, the average annual transfers volume in the financial assistance form to African countries is also estimated, and the dynamics of changes is calculated by the increment formula. Both values are averaged to data for 10 years because if there is a correlation on a smaller number of values, it will be more obvious. Also, Africa's development conditions allow suggesting a significant time lag. Then, the correlation between the obtained time series is calculated. By results, if:

(a) Correlation is high and positive, in this case, the help is effective;

(b) Correlation is high and negative, in this case, the assumption of a "financial assistance vicious circle" is fair and the help is harmful;

(c) Correlation is low, the sign is not important and in this case, help is ineffective, but it is also not harmful.

The correlation analysis is chosen to prove the connection or absence of connection between financial aid and economic growth - in normal conditions the first provokes the second. The supposition of the "financial assistance vicious circle" is based on the false belief in the availability of the foreign support for the national problems, leading to the deviational "cargo culture" on a national, not tribal level. In this regard, the negative correlation - the higher the volume of aid, the lower the economic growth signals that the country loses drivers for the development and substitutes it by the growth of foreign aid. The low correlation shows, that the use of financial aid leads to 
small and unstable results, so it proves the ineffectiveness of aid.

The factor analysis is nearly impossible to conduct due to the theoretical grounding of the explanation of the factor influence. Generally, the interpretation of the reasons of failure of aid to the African countries is based on theoretical findings and consists of the following: misuse of financial resources, corruption and low institutional quality, high crime level, unstable situation and the reluctant investors. The statistical proof for these findings is scarce and unreliable.

Further, the authors propose to consider Africa's current technological development state, after they offer a technological convergence developed model inside Africa. Then, the internal technological convergence model is supplemented by proposals for technological convergence mechanisms between countries (regions) and Africa.

This approach offers an effective mechanism for technological exchange as a tool for the region's development.

\section{The Assessment of Financial Aid Effectiveness}

To understand the general impact of foreign aid on the development of the recipient countries' economies, it is necessary to look at statistics of the aid volumes to compare it with the GDP growth volume in African countries (Figure 1).

As the data in Figure 1 shows, over such a long period, African economies' average growth did not exceed 3\%, which is extremely small, especially taking into account the low base effect, with an 3.5\% average world growth over the period [18]. It is necessary to notice the financial assistance volume to African countries is weakly correlated with economic growth: the calculated correlation was -0.13 , which indicates unreliability of the connection between these parameters. Moreover, with the aid growth, economic growth was more likely slowing down. Thus, it is easy to conclude that the effectiveness financial assistance in African countries since the growth of their economies is low.

The analysis of figure 1 reveals the following tendencies:

1) The growth of financial aid in the period between 1981 and 1990 resulted in the high GDP boost in 1991-2010, but the following downturn in the economic growth follows the downturn in financial aid;

2) The low growth rate of financial aid in 1981-2000 had little or no effect on the GDP growth in African countries, while the boost from the 1981-1990-s financial aid growth peak lasted;

3) The lag between the aid and the effect of the aid is close to 10 years;

4) The general growth of African economies is unreliable.

These conclusions are theoretical and their major task is to clarify the low effect of financial aid and the loose connection between them and economic growth. In addition to that, the conclusions №1 and №2 demonstrate the "formation of the financial aid vicious circle".

At the same time, we must not forget that before the adoption of the UN Sustainable Growth Goals, this concept was also applied in Africa; that's why this effect may be associated with the struggle against social inequality and health gaps, demographics and attempts to satisfy the needs of population in basic continent (figure 2).

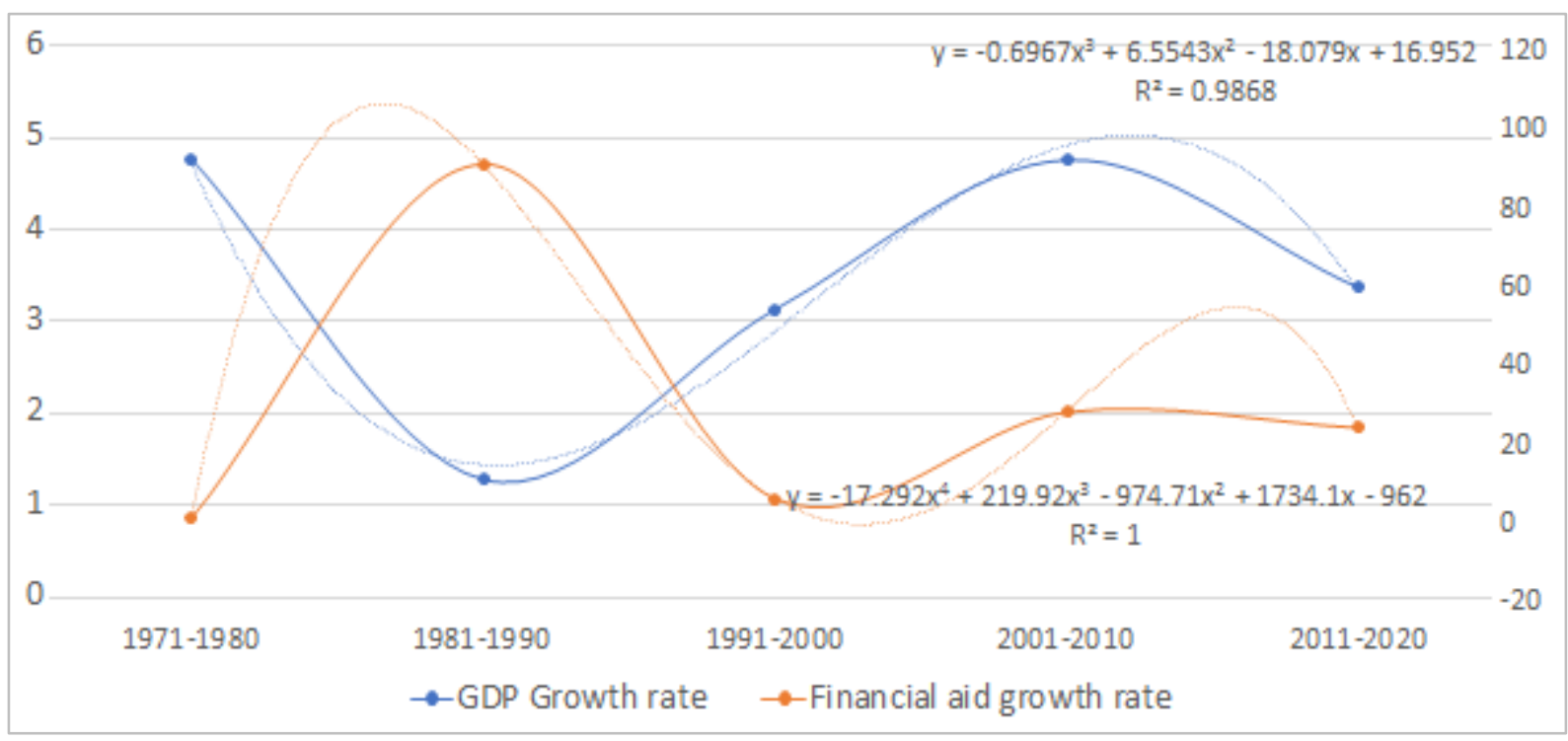

Figure 1. African countries' GDP growth and the financial assistance growth over a ten-year period (calculated by the author) [18], [17] 


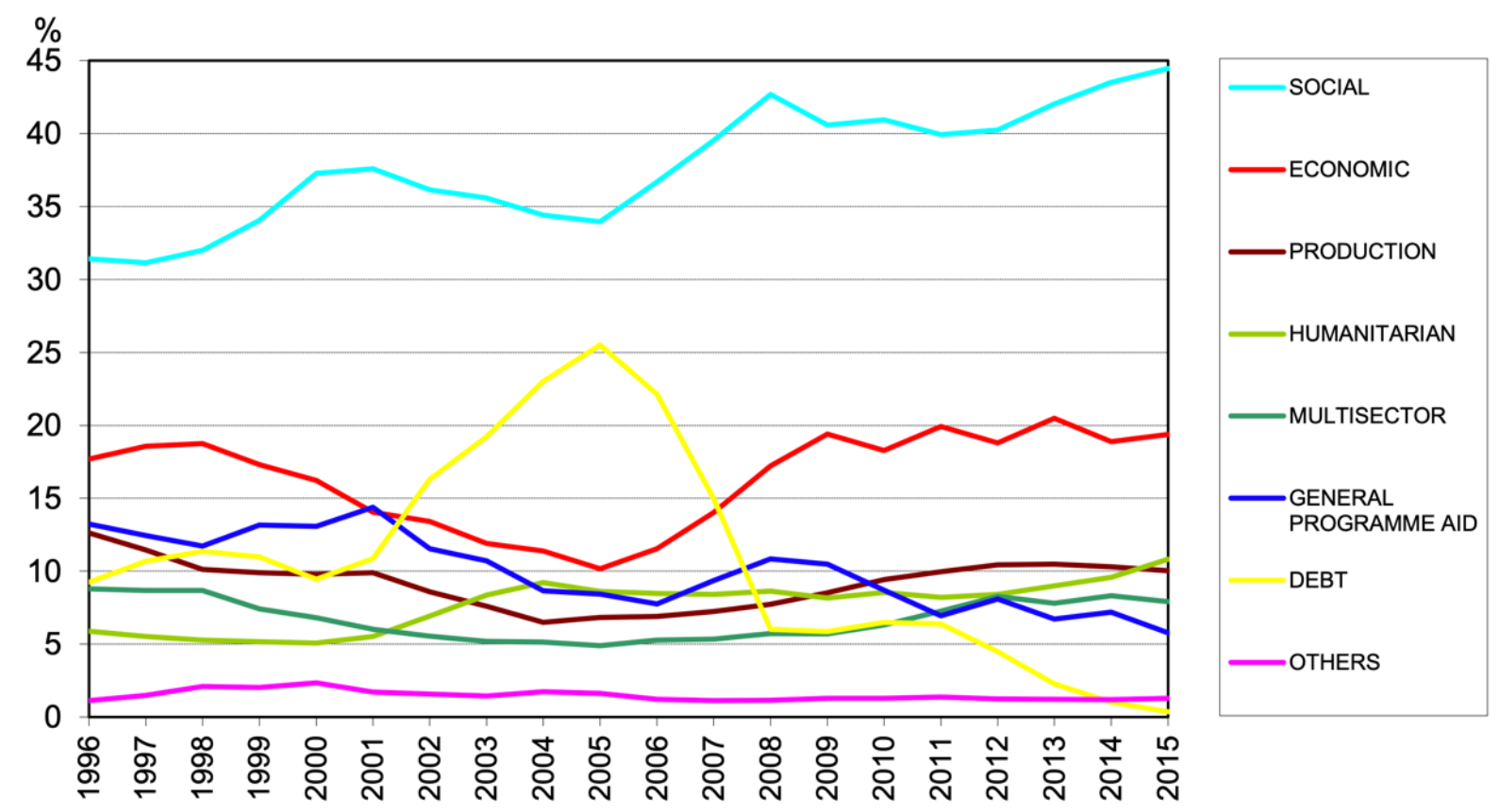

Figure 2. Assistance directions to African countries [17]

Thus, it can be stated that the assistance's social and humanitarian focus to African countries did not bring the desired result. It is also necessary not just to invest more in Africa in connection with the corruption high level [14], but it is necessary to create the conditions for effective investment. Sustainable Development Goals [20] suggest the new course formation in the economy, which aimed at green development and social equality. These goals are proposed for all countries, but before their unconditional adoption, it is necessary to make sure that countries do not have negative path dependence in relation to such goals [15]. As practice shows, assistance to the African countries was carried out mainly in the areas within these goals. Due to the growth lack, there is a high probability that African countries will have a negative experience within development programs realization in accordance with such a goal-setting.

In this regard, a new course of regional development is necessary; one of the possible directions may be technological development and digitalization (it is too early to talk about it in Africa, but its effects need to be assessed). Southeast Asian countries can be considered as an example of successful technological development; that's why the development model can be borrowed from them.

\section{Technology Development in Africa - Prospects}

Data Analysis [7] and [9] demonstrates that Africa has now taken the service approach path to technology. The data [2] confirms this theory, as it allows us to judge that the inclusiveness' growth in the Internet environment for African countries was not a growth source; this growth became an economic slowdown source and resources diversion's way, as it does not create a large increase in GDP (sector share is not more than $1.2 \%$ of GDP), but it requires significant financial investments. At the same time, the basis of the service economy is a productive economy: without goods production increase, there is no need to increase the number of services, especially in the least developed countries as such a bias also leads to financialization.

The authors consider technology as a growth source for African economies. It is widely known that most developed countries in the region, such as South Africa and Egypt, are countries with a low technological base [21], [12], wherein Egypt is one of the main financial assistance recipients from development institutions [17]. For South Africa, the most profitable option may be to obtain high technologies in the processing ores and raw materials field. These technologies will allow the country to use its mining industry more efficiently (!), while Egypt technological development should go towards the engineering sector creation, as the country is in demand among tourists (it can advertise its products without extra cost). It is also an important transport hub on the Europe-Asia route, which will allow it to export its products abroad.

Central Africa's least developed countries need basic medical technologies and technologies in the basic engineering field to ensure their demand for essential goods as these countries have not overcome the threshold of industrialization, and consequently, they need the technologies of the mid-20th century.

As practice shows, it is difficult to evaluate the technologies' value, as technologies are intangible assets. 
Since in some African countries the institute of joint research centers has been developed [9], it may be logical to start a technology transfer from there. To answering the question who can be a technology donor, international development institutions can be called: underdeveloped Africa is a direct indication of their inefficiency; European countries suffer from migration; and Asian countries, especially China, are seeking to increase their influence in the region. Each donor will have a different institutional technology transfer structure, the proposed technology transfer schemes are described below.

It is also necessary to form an institute for dissemination of the technology in Africa. For example, this can be a mechanism based on the African Development Bank. The Bank includes both the more developed countries and the most actively developing research programs. This allows us to talk about a technology transfer mechanism based on the time of technology transfer (Figure 3).

In figure 3 , the orange arrows show the scheme for transferring technologies and patents: developed countries transfer or sell certain technologies (patents for them) or place production with the right to receive used AFDB technologies (or to a country as directed by AFDB). In this case, they receive benefits in investment mode, deferred royalties' payment, or payment of the patent's value (the last two points from AFDB). The AFDB, in turn, transfers technologies to the countries, the most actively developing their own scientific sector. And these countries are obligated to transfer them to the least developed countries after the agreed time without compensation payment. The AFDB will receive financing for such activities from more developed economies, which will also receive these technologies, but on a paid basis and from raised funds.

In addition to the mentioned, the other international institutions, such as the AIIB, provide support to the African countries, AIIB, as an example, provided Ruanda with 200 million \$ and Egypt with 960 million \$, but the demand for capital isn't satisfied. The actions taken by the AfDB are far from enough. Map on the figure 4 demonstrates the activity of this institution in Africa. The majority of projects are aimed at the improvement of life in Africa (red dots), while energy, infrastructure and industrialization are paid less attention.
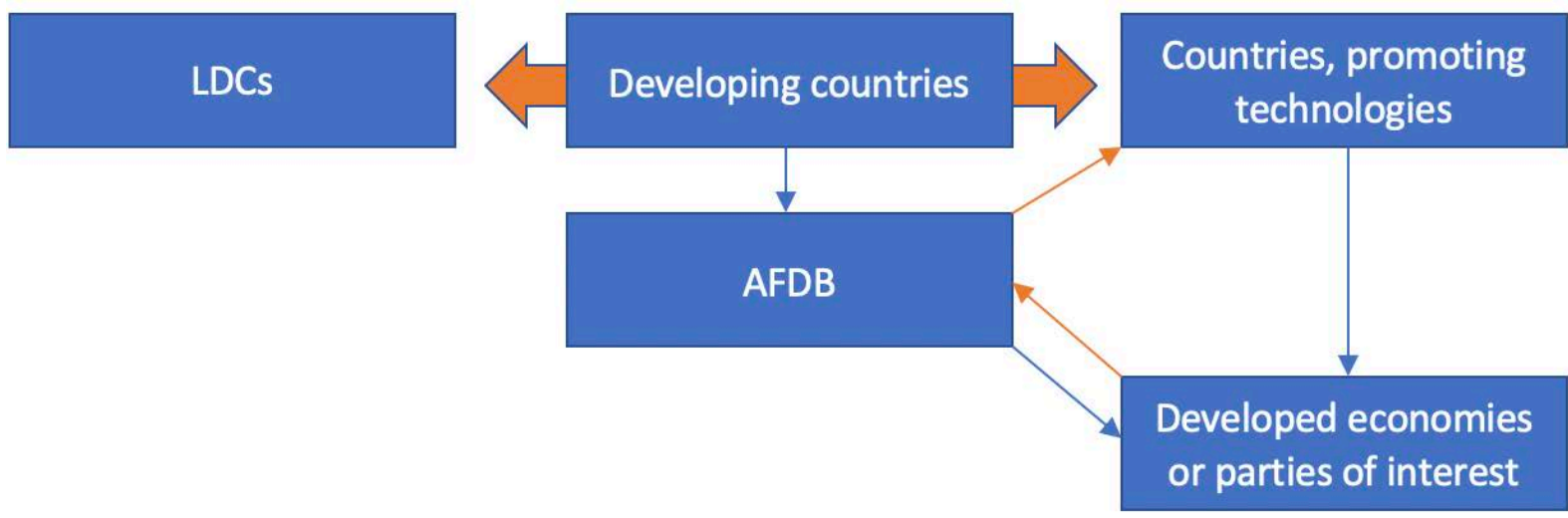

Figure 3. Technology development mechanism using AFDB (developed by the author) 


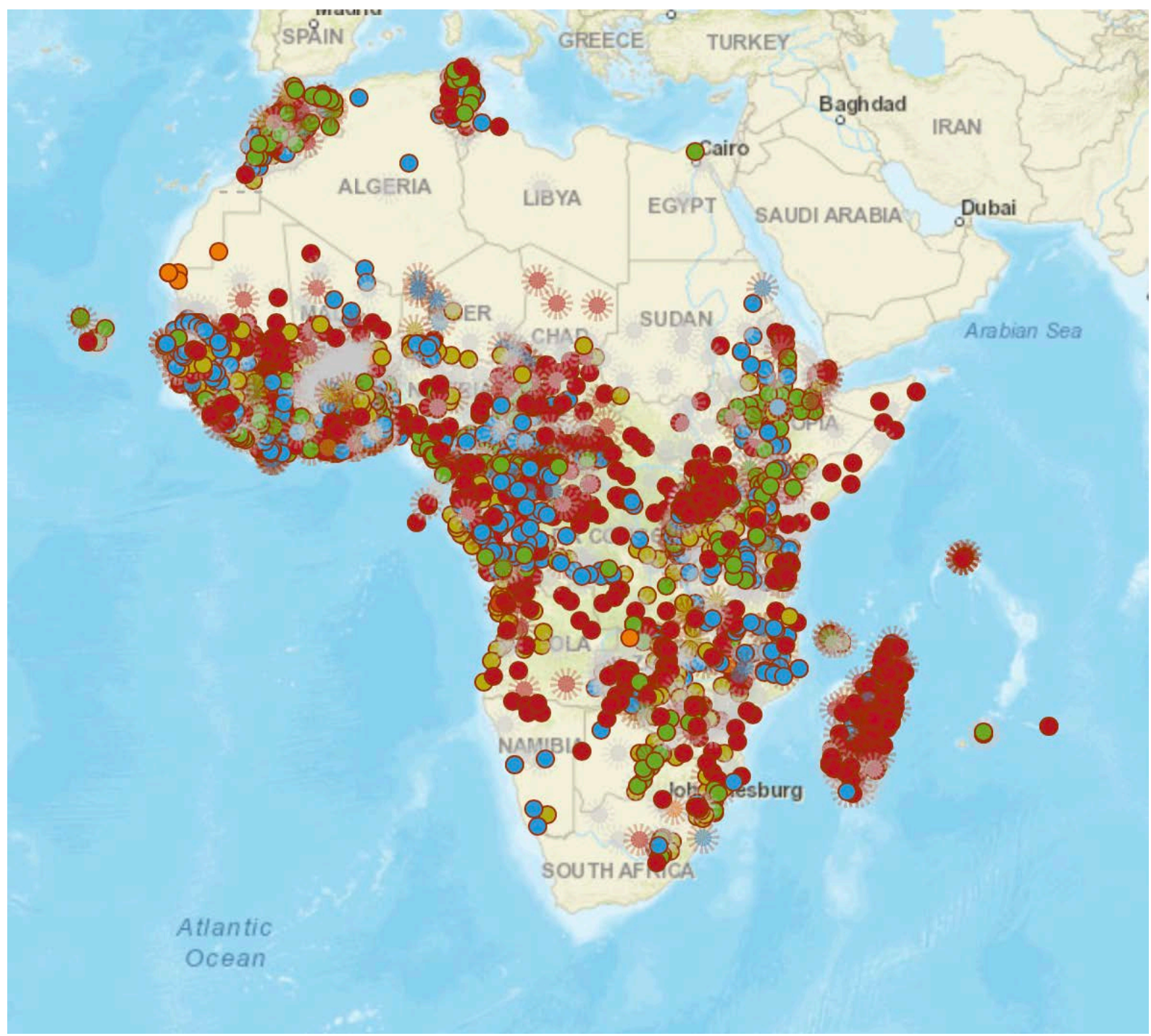

Figure 4. Projects of AfDB in Africa [25]

Figure 4 demonstrates clearly the wrong focus of the international organizations, along with the search for the better life for the African countries on cost of the international community with little or no prospects for the economic development, which in turn will lead to better living standards.

\section{Discussion}

As an analysis of the African development trends has shown, today the main attention is paid to the social sphere development, while the economy is primary to social security [13]. This problem can be solved by increasing the assistance volume on economic issues, but to avoid reducing the effectiveness of measures, being taken due to corruption, a proposal was put forward to use technological convergence as a tool for stimulating African economies development. The authors suggested a mechanism for the internal technology convergence on the continent, having mentioned that interested parties can participate in this mechanism. We offer the most probable scenarios for cooperation.

1) Collaboration with supranational institutions. As already suggested above, supranational institutions, such as development banks actively cooperate with countries from different regions. This is a great advantage for those states that are ready to both acquire and sell technologies because it is possible to create a technology exchange on the basis of such institutions. Taking into account at least one development bank exists in each region within the proposed scheme, it is logical to suggest technology trade organizing between development banks on favorable terms for the AFDB. This process seems difficult, but from the viewpoint of developed countries and dynamically developing economies, the obsolete technologies sale will be a profitable step.

2) On the basis of AfDB and AIIB, an agreement about Chinese investment to Africa can be created, because 
AIIB is one of the Chinese institutions within the "One Belt, One Way" initiative. If investments come in the priority sectors' list, then at the investor's request, he can be exempted from taxes for a certain period in exchange for the certain technologies transfer. A similar financial stimulation mechanism should work for other countries, but on the basis of the AFDB. Within this mechanism realization, priority should be given to regional development banks: institutions such as the World Bank Group are inflexible in the issue of the Africa's development and they will slow down with a high probability the technological convergence process.

3) An ambitious task may become the agreement signing about technological convergence on the above conditions between the AfDB (or the African Union) and BRICS, as such a mechanism will reduce transaction costs during technology transfer, because South Africa is a BRICS' member and it one of the most developed countries in the region. Within this mechanism, it is possible to expand the agreement not only on investments but also on joint ventures. The authors also suggest expanding the mechanism of such agreements at the EAEU.

The proposed mechanisms give opportunities for African countries to achieve a high development level in a short time because technological cooperation accelerates development. However, their realization is difficult due to the absence of proven mechanisms for South-South cooperation and mechanisms for cooperation with Africa [16], [19]. In this regard, it is necessary to begin the negotiation process as soon as possible.

\section{Conclusions}

The development trends of African countries in accordance with the proposed Sustainable Development Goals have shown their inefficiency and the institution are ineffective, too. To create conditions for the development of a sustainable region, it is necessary to use other approaches.

As suggested by the authors, the alternative approach to Africa's development on the basis of technological convergence and digitalization (which will follow technological development) may be more effective and less costly than the principle of direct financial assistance, providing through development institutions, which is applied today.

The technological convergence principle which is the basis of the approach should stimulate the equitable and sustainable development of the least developed countries in the region; that's why it requires the participation of structures streamlining the technology transfer process. The African Development Bank looks like the most attractive institution in this regard.
External technological convergence should be based on the cooperation of supranational institutions within favorable conditions creating for countries which are ready to transfer technology for free. For this, fiscal stimulating measures and a deferred financial flow for technology payments are proposed.

\section{REFERENCES}

[1] Akobeng, E. "Harnessing foreign aid for the poor: role of institutional democracy”, Journal of Economic Studies, Vol. 47 No. 7, 2020, pp. 1689-1710. https://doi.org/10.1108/JES05-2019-0225

[2] African Development Bank Group. “Tracking Africa's Progress in Figures”, 2014. https://www.afdb.org/fileadmin/ uploads/afdb/Documents/Publications/Tracking_Africa\%E2 \%80\%99s_Progress_in_Figures.pdf

[3] Andrews, Nathan. "Foreign aid and development in Africa: What the literature says and what the reality is", Journal of African Studies and Development Vol. 1(1), 2009, pp. 008-015.https://academicjournals.org/article/article1379931 879_Andrews.pdf

[4] Asongu, S.A. Nnanna, J. "Foreign Aid, Instability, and Governance in Africa”, Politics Policy, 47, 2019, pp. 807-848. https://doi.org/10.1111/polp.12320

[5] Birdsall, Nancy. "The Dilemma of the African Development Bank: Does Governance Matter for the Long-Run Financing of the MDBs?.” 2018. CGD Working Paper 498. Washington, DC: Center for Global Development. https://www.cgdev.org/publication/dilemma-afdb-does-gove rnance-matter-long-run-financing-mdbs

[6] Cai, J., Zheng, Z., Hu, R., Pray, C. E., \& Shao, Q. "Has International Aid Promoted Economic Growth in Africa?”, African Development Review, 30(3), 2018, pp. 239-251. https://doi.org/10.1111/1467-8268.12333

[7] Carroll, Anthony, Obscherning, Eric. “Africa Trade and Technology”, Issue 119, 2019. https://www.hoover.org/rese arch/africa-trade-and-technology

[8] Davis, Steve, Woetzel, Jonathan. "It's time to move beyond sterile arguments and accept China's role in Africa. But it's also time for China to enhance that role”, 2010. https://www.mckinsey.com/industries/public-and-social-sect or/our-insights/making-the-most-of-chinese-aid-to-africa

[9] Dews, Fred. "Charts of the Week: Technology and industry in Africa”, 2019.https://www.brookings.edu/blog/brookings -now/2019/03/01/charts-of-the-week-technology-and-indust ry-in-africa

[10] Gupta, Sanjeev, Powell, Robert, Yang, Yongzheng. "Macroeconomic Challenges of Scaling Up Aid to Africa A Checklist for Practitioners”, 2006, pp. 1-79. https://www.imf.org/external/pubs/ft/afr/aid/2006/eng/aid.p df

[11] Hofmeier, Rolf. "Political conditions attached to development aid for Africa”, Intereconomics, Verlag Weltarchiv, Hamburg, Vol. 26, Iss. 3, 1991, pp. 122-127, 
http://dx.doi.org/10.1007/BF02926122

[12] Kirlidog, Melih, Charles van der Vyver, Malie Zeeman, and Wilma Coetzee. "Unfulfilled need." Information Development 34.1. 2018. pp. 5-19.

[13] Knutsen, Tora, Kotsadam, Andreas. “The political economy of aid allocation: Aid and incumbency at the local level in Sub Saharan Africa”, World Development, Volume 127, 2020, 104729, https://doi.org/10.1016/j.worlddev.2019.1047 29

[14] Momoh, Zekeri. "Corruption and governance in Africa”, Conference: International Multi-Disciplinary Academic Conference on African Transformation and Development organized by Cambridge Publications and Research InternationalAt: University of Ilorin, Ilorin Kwara stateVolume: Vol. 3 No. 10. 2015.

[15] Navarro-Pabsdorf RM, Martínez-Alcalá C, Moral-Pajares E. "Can International Trade Help Africa's Least Developed Countries Achieve SDG-1?”, Sustainability. 2020, 12(11), 4470. https://doi.org/10.3390/su12114470

[16] Ngameni, J.P. Khan, M.A. "Technological Innovations in the Control of International Exchange: Lessons for Africa”, African Development Review, 31, 2019, pp. 129-143. https://doi.org/10.1111/1467-8268.12368

[17] OESD. "Development aid at a glance statistics by region”, 2018. https://www.oecd.org/dac/financing-sustainable-devel opment/development-finance-data/Africa-Development-Aid -at-a-Glance-2018.pdf
[18] The World Bank. "GDP growth (annual \%) - Sub-Saharan Africa (excluding high income)”, 2021. https://data.worldba nk.org/indicator/NY.GDP.MKTP.KD.ZG?locations=ZF

[19] UNSTAD. "Key issues for African countries in Science, Technology and Innovation”, 2013. https://www.un.org/en/e cosoc/newfunct/pdf13/wipo_ecosoc_amr_dar_13_e_sampat h.pdf

[20] UN. "Take Action for the Sustainable Development Goals" 2021.https://www.un.org/sustainabledevelopment/sustainab le-development-goals

[21] Wako, Hassen Abda. "Effectiveness of foreign aid in sub-Saharan Africa: Does disaggregating aid into bilateral and multilateral components make a difference?”, Journal of Economics and International Finance 3(16), pp. 801-817. DOI: $10.5897 / J E I F 11.126$

[22] Zakhary, Nadia. "Science, Technology and Innovation in Egypt”, 2013. https://www.un.org/en/ecosoc/newfunct/pdf1 3/wipo_ecosoc_amr_dar_13_a_zakhary.pdf

[23] Kobayashi, Yoshiharu, Heinrich, Tobias, A. Bryant , Kristin. Public support for development aid during the COVID-19 pandemic. 2021. https://www.ncbi.nlm.nih.gov/pmc/articles /PMC7577681/

[24] Mary Izobo. The Impact of Foreign Aid in Africa: A case study of Botswana and Somalia. 2019. Journal on rule of law. Volume 5. Pp1-13.

[25] African development bank group. Map Africa. https://mapafrica.afdb.org/en/ 